\title{
Tailored disconnection based on presurgical evidence in catastrophic epilepsy: report of 2 cases
}

\author{
Jun T. Park, MD, ${ }^{1,2}$ Sunil V. Manjila, MD, ${ }^{3}$ Rachel B. Tangen, PhD, ${ }^{4}$ Mark L. Cohen, MD, ${ }^{5}$ \\ Asim M. Shahid, MD, ${ }^{1,2}$ Jennifer A. Sweet, MD, ${ }^{3}$ Ingrid E. Tuxhorn, MD, ${ }^{1}$ and Jonathan P. Miller, MD $^{3}$ \\ 1Section of Pediatric Epilepsy and ${ }^{4}$ Division of Developmental and Behavioral Pediatrics and Psychology, Department of \\ Pediatrics, Rainbow Babies \& Children's Hospital; '2Epilepsy Center and ${ }^{3}$ Department of Neurosurgery, Neurological Institute; and \\ ${ }^{5}$ Department of Pathology, University Hospital, Case Western University School of Medicine, Cleveland, Ohio
}

\begin{abstract}
Catastrophic epilepsy in infants, often due to extensive cortical dysplasia, has devastating consequences with respect to brain development. Conventional lobar, multilobar, or hemispheric resection in these infants is challenging, carrying an increased operative risk compared with that in older children. Removing a larger tissue volume versus removing or disconnecting the epileptogenic region does not always guarantee better seizure outcome. The authors describe 2 infants with catastrophic epilepsy who benefited from individually tailored disconnections based on a hypothesized epileptogenic zone following intensive presurgical evaluation.

Two infants with catastrophic epilepsy and epileptic spasms underwent leukotomies between 3 and 12 months of age. They were followed up postoperatively for $19-36$ months. Both patients had $90 \%-100 \%$ seizure reduction and a significantly improved neurodevelopmental outcome without postoperative complication. Cortical malformation was seen in both patients. Modifications of established surgical disconnection techniques, tailored to each patient's specific epileptogenic zone, optimized seizure and neurodevelopmental outcomes while minimizing the risks associated with more extensive resections.
\end{abstract}

http://thejns.org/doi/abs/10.3171/2015.11.PEDS15495

KEY WORDS disconnection; leucotomy; catastrophic epilepsy; epileptic spasms; cortical dysplasia; epileptogenic zone; seizure semiology; epilepsy surgery

1 PROLONGED duration of uncontrolled seizures before 2 years of age results in irreversible global developmental delay. ${ }^{5}$ Therefore, early epilepsy surgery during the period of brain plasticity to relieve the brain of seizure burden is critical for brain development. ${ }^{1}$ Conventional resective surgery in infants with extensive cortical dysplasia (CD) is challenging and carries an increased operative risk compared with that in older children. ${ }^{6}$ Leucotomy in infants minimizes perioperative complications. ${ }^{2}$ In the cases described here, instead of identifying patients who might benefit from the established surgical disconnection techniques, we modified the disconnection procedure for each patient based on the location of the epileptogenic zone.

\section{Case Reports}

Case 1

History and Examination

An infant boy, who had been born full term, began hav- ing seizures at 4 months of age, when he presented with focal status epilepticus characterized by a left versive seizure followed by a left limb clonic seizure that generalized. When the boy was 5 months of age, while on phenobarbital, video electroencephalography (EEG) showed sharp waves and intermittent slowing in the right parietooccipital region. Additionally, multiple clinical seizures originating from the right parietal region and lasting up to 10 minutes were recorded. Seizure semiology showed arrest of activity followed by left eye nystagmus. Interictal FDG-PET revealed hypometabolism in the posterior right temporal, parietal, occipital (TPO) lobes and inferior left temporal lobes. Ictal and interictal SPECT scans showed no difference from one another.

When the boy was 9 months of age, additional seizuretype, nonlateralized epileptic spasms began. In addition, postictal left eyelid droop was associated with left facial clonic seizures. Neuropsychological evaluation demonstrated deficits in the areas of gross motor, receptive language, and visual perception skills. The epileptogenic zone

ABBREVIATIONS AED = antiepilepsy drug; $C D$ = cortical dysplasia; $E E G=$ electroencephalography; ILAE = International League Against Epilepsy; MSEL = Mullen Scales of Early Learning; PLED = periodic lateralized epileptiform discharge; TPO = temporal, parietal, occipital.

SUBMITTED August 13, 2015. ACCEPTED November 2, 2015.

INCLUDE WHEN CITING Published online February 12, 2016; DOI: 10.3171/2015.11.PEDS15495. 
was thought to be in the right parietooccipital lobe based on 1) congruent data on 3-T MRI and ictal FDG-PET (Fig. $1 \mathrm{~A}$ and B),2) congruent ictal and interictal EEG localization, and 3) left hemiparesis and postictal left eyelid droop.

\section{Operation}

When the boy was 11 months old, a right TPO disconnection (Fig. 1C and D) was performed. It was a modification of the periinsular hemispherotomy, such that the suprasylvian portion of the procedure consisted only of a leucotomy along the postcentral sulcus to the midline with posterior callosotomy to disconnect the temporal, occipital, and posterior parietal lobes while preserving the frontal and central structures. After a temporoparietal craniotomy, a leucotomy was performed along the postcentral sulcus and deepened to the midline pia. The atrium of the lateral ventricle was entered, and from within the ventricle the splenium of the corpus callosum and fornix were transected. The leucotomy was extended across the sylvian fissure following the ventricle anteriorly to the tip of the temporal horn. The mesial temporal structures were then resected. Care was taken to preserve all vessels.

\section{Postoperative Course}

Histopathology of the superior temporal and occipital gyri demonstrated CD International League Against Epilepsy (ILAE) Type I. Six months after surgery, neuropsychological testing showed improvement in all domains with deficits in fine motor and language skills, despite a pervasive developmental disorder. Preoperative left hemiparesis (Grade 4 of 5) with left-sided neglect did not change postoperatively. He had a mild subgaleal collection at the surgical site that subsequently resolved. Moreover, fever from an unknown cause on Day 1 after surgery resolved without complication.

The boy remained seizure free for 22 months (Engle Class IA), the latter 5 months without antiepilepsy drugs (AEDs). At 3 years of age, he remained only on oxcarbazepine, with a seizure characterized by bilateral limb stiffening progressing to left limb clonus and occurring with a frequency of about 5 per year (Engle Class IB).

\section{Neuropsychological Evaluations}

Two standardized tests were administered in this case: Mullen Scales of Early Learning (MSEL) and Vineland Adaptive Behavior Scales-Second Edition, Parent/Caregiver Rating. When the boy was tested at 10 months of age, before the surgery, his composite score on the MSEL was in the average range (standard score 105); however, his individual domain performance was variable. His expressive language and fine motor domains were in the average range, while his gross motor, visual reception, and receptive language domains were in the impaired range. He showed lateralizing visual and motor symptoms on the left side of the body, indicating right hemisphere brain involvement. His parents' ratings of adaptive functioning were in the low average range (standard score 84,14 th percentile) with delays reported in language and motor skills. Six months after surgery, his composite score on the MSEL was in the low average range (standard score 86, 18th percentile). While raw scores increased in all domains, standard

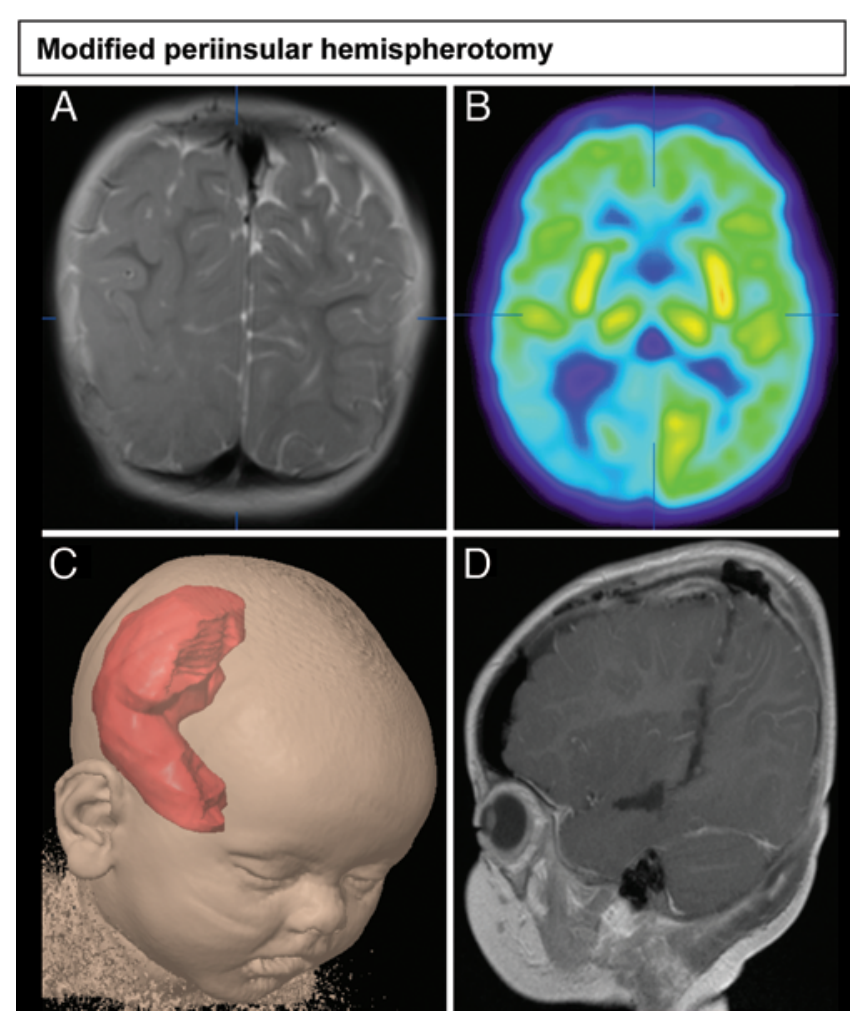

FIG. 1. Case 1. A: Preoperative coronal T2-weighted MR image showing $C D$ in the left occipital lobe. B: Preoperative FDG-PET scan showing hypometabolism in the left occipital lobe. C: Preoperative BrainLab image of an area of epileptogenicity disconnected from the rest of the brain with a single continuous cut through the white matter. D: Postoperative sagittal T1-weighted MR image showing the disconnected TPO region. Figure is available in color online only.

scores indicated that he was not making the same amount of progress as same-age peers in fine motor and expressive and receptive language domains. In contrast, gross motor and visual reception performance significantly improved. A possible explanation for this lag in language progression was the fact that the boy underwent neurosurgery and intervention during a critical language development window, which may have caused a delay in this domain. At 2 years of age, he was speaking in sentences of 5 words and made improvements in left arm function. He had about 100 words in his vocabulary and was putting together 2-word sentences. By 3 years of age, his social-emotional development was appropriate for his age, and his speech was $75 \%$ understandable while using 2- to 3-word sentences.

\section{Case 2}

History and Examination

An 18-day-old female infant, who had been born full term, presented to our hospital with status epilepticus characterized by asynchronous myoclonic jerks involving all limbs. These were associated with eye deviation to the right and occurred every 1-2 seconds. In addition, she had intermittent right lip, right arm, and right leg clonic seizures lasting several seconds, which increased in frequency to 1 every few minutes. Brain MRI revealed a prominent focus of abnormal signal extending from the left medial frontal 
cortex to the ventricular surface (Fig. 2A). The diagnosis of tuberous sclerosis was supported by the presence of cardiac rhabdomyomas on cardiac ultrasonography. Seizures were managed with levetiracetam and phenobarbital.

When the girl was 3 months of age, a diagnosis of tuberous sclerosis with the TSC1 mutation was genetically established, and she developed daily bilateral asymmetrical and symmetrical epileptic spasms lasting 20-30 minutes. These spasms were preceded by right lip twitching and right limb clonic seizures lasting approximately 10 seconds. Interictal EEG showed left centroparietal spikes/ polyspikes (maximum negativity at C3; frequency of 1 sharp wave every 15-30 seconds), frequently appearing as periodic lateralized epileptiform discharges (PLEDS). The epileptic spasms showed widespread epileptiform discharges on EEG. Vigabatrin was added to the levetiracetam and phenobarbital. The FDG-PET studies showed nonspecific hypometabolism bilaterally. The epileptogenic zone was thought to be at or in the neighborhood of the left frontal tuber based on 1) right lip, arm, and leg clonic seizures evolving into epileptic spasms; 2) interictal left centroparietal PLEDS; and 3) MRI showing a left superior frontal cortical lesion.

\section{Operation}

When the girl was 3 months old, a modified parasagittal hemispherotomy was performed, omitting the lateral thalamic and forniceal transections and thus preserving the posterior frontal, temporal, and parietal structures. After craniotomy, the tuberous lesion was identified in the superior frontal sulcus and resected. The lateral ventricle was entered, and the rostrum of the corpus callosotomy was transected. A leucotomy was then performed from the frontal horn to the base of the anterior cranial fossa at the level of the anterior communicating artery and extended laterally to the convexity to disconnect the anterior frontal lobe (Fig. 2B-D). Intraoperatively, she had a small fracture from the cranial fixation device, which was repaired.

\section{Postoperative Course}

No postoperative complication occurred. Histopathology of the biopsy sample from the frontal lobe revealed focal CD ILAE Type IIB without balloon cells. Postoperative head CT showed a pseudomeningocele, fever of no clear etiology (limited to Day 1), and mild weakness in the right limbs during the 1st week after surgery. She had 1 right arm clonic seizure during the first few days after surgery. Subsequently, she was seizure free on a lowered dose of levetiracetam.

\section{Neuropsychological Testing}

No formal neuropsychological testing was performed given the girl's young age. Thus, assessment of the developmental outcome was based on follow-up evaluations in the epilepsy, neurology, and pediatric clinics. Developmental milestones improved as the epileptic encephalopathy resolved. By 5 months of age, she was making vocal noises, playing with her hands, smiling, and laughing. She was attaining head control and attempting to roll sideways. By 2 years of age, she had approximately 10 words in her vocabulary and was ambulating independently.

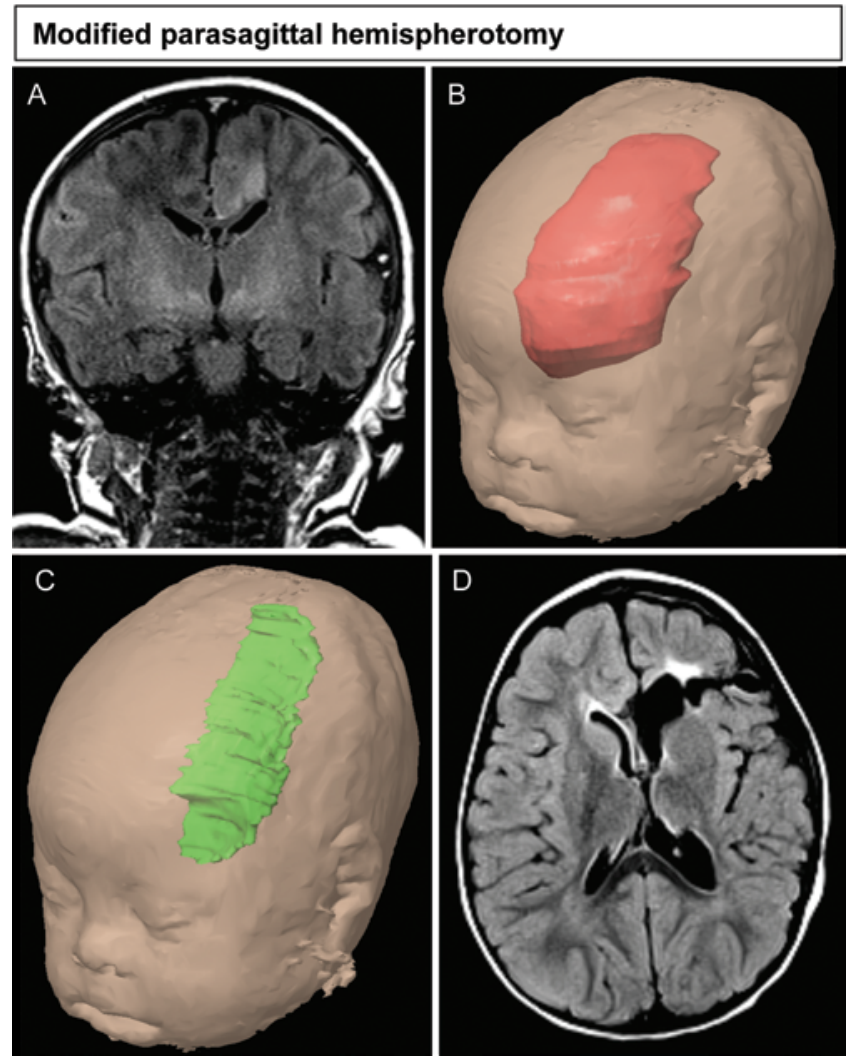

FIG. 2. Case 2. A: Preoperative coronal MR image showing a hyperintense lesion in the left mesial frontal lobe, extending anteroposteriorly approximately $32 \mathrm{~mm}$. B: Preoperative planning BrainLab image showing an area of epileptogenicity disconnected from the rest of the brain. C: Preoperative planning BrainLab image showing the site of a single continuous cut through white matter separating the epileptogenic tissue. D: Postoperative axial MR image showing the left frontal lobe disconnected rostral to the precentral gyrus. Figure is available in color online only.

\section{Discussion}

All surgeries were performed by a single neurosurgeon with an assistant at a university-based hospital. Both patients had 90\%-100\% seizure reduction and a significantly improved neurodevelopmental outcome after the tailored disconnections (Table 1). Our 2 patients had catastrophic epilepsy, and their overall outcomes are consistent with data published by Duchowny et al. ${ }^{4}$ A long-term study ( $>2$ years postsurgery) is needed in infants who undergo tailored disconnections specifically for cortical malformation to validate our results.

Postoperatively, the patient in Case 1 had frequent electrographic seizures localized only to the disconnected right parietal lobe and no clinical signs. Thus an incomplete disconnection, although possible, does not appear to explain the recurrence of different seizure types at the onset. This may suggest the presence of CD outside the disconnected TPO region.

An invasive investigation was not done in the patient in Case 2 because evaluation with depth electrodes is extremely difficult, if not impossible, in a 3-month-old patient and would probably not have changed our plan to disconnect the left frontal lobe. A hemispherotomy was considered to address EEG involvement of the centropa- 
TABLE 1. Clinical parameters in 2 patients*

\begin{tabular}{|c|c|c|}
\hline & Case 1 & Case 2 \\
\hline Age at seizure onset & 4 mos & 18 days \\
\hline Comorbidity & Rt gaze preference, developmental delay & $\begin{array}{l}\text { TSC1, cardiac rhabdomyoma, tetherd cord, It leg lymph- } \\
\text { edema, rt gaze preference, developmental delay }\end{array}$ \\
\hline Age at surgery (mos) & 11 & 3 \\
\hline $\begin{array}{l}\text { Contralat interictal epileptiform } \\
\text { discharges (preop } \rightarrow \text { postop) }\end{array}$ & No $\rightarrow$ no (ipsilat rt frontal) & $\mathrm{No} \rightarrow \mathrm{no}$ \\
\hline Seizure types (preop $/ / \rightarrow$ postop) $\dagger$ & $\begin{array}{l}\text { 1. Lt versive } \rightarrow \text { It limb clonic } \rightarrow \text { generalized motor } / / \rightarrow \\
\text { 1. Hypomotor } 2 \text {. Bilat limb tonic } \rightarrow \text { It limb clonic }\end{array}$ & $\begin{array}{l}\text { 1. Asynchronous myoclonic } 2 \text {. Rt limb clonic } \rightarrow \text { epileptic } \\
\text { spams } / \rightarrow \text { none }\end{array}$ \\
\hline Interictal EEG findingsł & $\begin{array}{l}\text { 1. Rt parieto-occipital sharp waves } 2 \text {. Intermittent } \\
\text { slowing }\end{array}$ & Lt centro-parietal PLEDS \\
\hline EEG epileptogenic zone & Rt parieto-occipital & Lt frontal lesion \\
\hline $\begin{array}{l}\text { Epileptogenic zone localization } \\
\text { based on }\end{array}$ & $\begin{array}{l}\text { Congruent data in 3-T MRI \& ictal FDG-PET; } \\
\text { congruent ictal \& interictal EEG localization; It } \\
\text { hemiparesis \& postictal It eyelid droop }\end{array}$ & $\begin{array}{l}\text { Rt lip, arm, \& leg clonic seizures evolving into epileptic } \\
\text { spasms; interictal It centroparietal PLEDS; MRI: It } \\
\text { superior frontal cortical lesion }\end{array}$ \\
\hline Type of disconnection performed & TPO disconnection, modified rt & hemispherotomy, modified It \\
\hline Pathology sample & FCD Type I, superior temporal, occipital & FCD Type IIB, frontal \\
\hline Motor outcome (pre $\rightarrow$ post) & Lt hemiparesis $\rightarrow$ It hemiparesis & Normal (postop mild rt hemiparesis $\times 1$ wk) \\
\hline FU (mos) & 37 & 26 \\
\hline $\begin{array}{l}\text { Longest seizure-free period } \rightarrow \\
\quad \text { seizure outcome (Engel class) }\end{array}$ & $22 \mathrm{mos} \rightarrow \mid \mathrm{B}$ & $26 \mathrm{mos} \rightarrow \mathrm{IA}$ \\
\hline AEDs (pre $\rightarrow$ post) & LEV, $\mathrm{PHB} \rightarrow \mathrm{OXC}$ & LEV, PHB, VGN $\rightarrow$ none \\
\hline FDG-PET & $\begin{array}{l}\text { Interictal hypometabolism: posterior rt TPO, inferior } \\
\text { It temporal }\end{array}$ & No lateralization \\
\hline SPECT (baseline, interictal) & Negative & Not done \\
\hline MRI cortical lesion & Rt TPO, inferior It temporal & Lt superior frontal \\
\hline
\end{tabular}

$\rightarrow=$ seizure progression; $/ /=$ after surgery; FCD = focal CD; FU = follow-up; LEV = levetiracetam; OXC = oxcarbazepine; $P H B=$ phenobarbital; VGN = vigabatrin

* Neither of the patients had postoperative complications.

$\dagger$ Different seizure types are denoted by a number.

$\ddagger$ Different types of findings are denoted by a number.

rietal region in addition to the frontal lobe MRI lesion. However, this technique would have resulted in hemianopia and most likely a hemiparesis.

Convergence of data in both patients allowed for the formulation of a sound hypothesis regarding the epileptogenic zones. All patients had overwhelmingly abundant interictal and ictal EEG abnormalities and seizure semiology that were lateralizing and localizing. In carefully selected infants, modification of classic disconnection techniques minimizes the size of the resection cavity. This most likely reduces perioperative morbidity and long-term complications such as hydrocephalus ${ }^{3}$ while optimizing seizure control, allowing the patients to progress.

\section{References}

1. Asarnow RF, LoPresti C, Guthrie D, Elliott T, Cynn V, Shields WD, et al: Developmental outcomes in children receiving resection surgery for medically intractable infantile spasms. Dev Med Child Neurol 39:430-440, 1997

2. Daniel RT, Meagher-Villemure K, Farmer JP, Andermann F, Villemure JG: Posterior quadrantic epilepsy surgery: technical variants, surgical anatomy, and case series. Epilepsia 48:1429-1437, 2007

3. Daniel RT, Meagher-Villemure K, Roulet E, Villemure JG: Surgical treatment of temporoparietooccipital cortical dysplasia in infants: report of two cases. Epilepsia 45:872-876, 2004
4. Duchowny M, Jayakar P, Resnick T, Harvey AS, Alvarez L, Dean P, et al: Epilepsy surgery in the first three years of life. Epilepsia 39:737-743, 1998

5. Huttenlocher PR, Hapke RJ: A follow-up study of intractable seizures in childhood. Ann Neurol 28:699-705, 1990

6. Olavarria G, Petronio JA: Epilepsy surgery in infancy. A review of four cases. Pediatr Neurosurg 39:44-49, 2003

\section{Disclosures}

The authors report no conflict of interest concerning the materials or methods used in this study or the findings specified in this paper.

\section{Author Contributions}

Conception and design: Park. Acquisition of data: Park, Manjila, Cohen, Shahid, Miller. Analysis and interpretation of data: Park. Drafting the article: Park, Tangen, Sweet. Critically revising the article: Park, Sweet, Tuxhorn. Reviewed submitted version of manuscript: Park. Approved the final version of the manuscript on behalf of all authors: Park. Study supervision: Miller.

\section{Correspondence}

Jun T. Park, University Hospitals, Pediatrics, 11100 Euclid Ave., Mailstop 6009, Cleveland, OH 44106. email: jun.park@ uhhospitals.org. 